for the $\mathrm{PhD}$ degree in six groups of subjects-biology, chemistry, engineering, earth sciences, mathematics and physics. The report of the chemistry group was published in March last year, and the Royal Society hopes that the reports of the other four groups will appear before the end of 1968 .

The physics sub-committee, under Professor C. C. Butler of Imperial College, limited its attention to a study of postgraduate lecture courses attended by physics PhD students and a comparison with courses available in graduate schools in the United States. Butler sent a letter to the heads of all university physics departments asking for brief details of postgraduate lecture courses attended by $\mathrm{PhD}$ students, and it is on the replies to this letter that the new report is based. Rather surprisingly, the sub-committee did not ask the $\mathrm{PhD}$ students themselves for views on postgraduate training.

The present undergraduate course is no longer sufficient to prepare students for a full professional career, and the report approves of the recent trend towards lecture courses for PhD students. The subcommittee realizes that it is often difficult for experimentalists to complete a $\mathrm{PhD}$ within the three years of a Science Research Council maintenance grant, and any extension of course work will increase the difficulties. It therefore recommends that provisions for fourth year grants should be made in certain cases.

Comparison with graduate schools in the United States-largely based on the opinions of British physicists who have worked in American universitiesrevealed no evidence that the standards of $\mathrm{PhD}$ training are significantly different in the two countries. There seems, however, to be some foundation for the widely held view that the American experimentalist has a broader theoretical knowledge than his British counterpart.

Some of the value of these six studies of postgraduate training in science and technology is being lost because the organization of the surveys is being left to the discretion of the individual chairmen. The chemistry report, for instance, was based on enquiries among university professors and six centres of chemistry in the United States, while the more ambitious sub-committee for engineering has written to 1,900 postgraduates and to 90 companies and institutions. This will make comparison of the training afforded to students in different subject groups difficult.

\section{Soul-searching for ESRO}

ON Wednesday and Thursday of this week there was a meeting of Alternates of the European Space Research Organization (ESRO) where the main preoccupation was expected to be the continuing exercise of preparing ESRO's case (see Nature, 216, 696; 1968) for the European Space Conference in Bonn in June. It is hoped that here a policy and programme for European space will finally be settled. At the last European Space Conference, in Rome last July, a special committee was set up to evaluate the various proposed projects in European terms. This Advisory Committee on Programmes was chaired by J. P. Causse from the French aerospace industry, supported on the technical side by five independent experts, and it produced its report at the turn of the year. The ESRO Alternates were to consider it in detail at this week's meeting. There seems no reason why the Causse Committee's report should not then be published.

The main dilemma facing ESRO is whether its activities should be substantially redirected towards "useful" satellites, such as the communications satellite sponsored by CETS (the European Conference for Telecommunications by Satellite), or retain its original purpose of providing scientific research opportunities beyond the resources of individual countries. The immediate clash is between the European communications satellite and the large astronomical satellite as candidates for ESRO's major project for its first decade. It seems out of the question that both projects could be adopted at the present financial level of European space organizations. It will be interesting to see what the Causse Committee has had to say about their relative merits.

\section{Full Stop on Decimals}

Britain's plans to adopt the metric system of units have run into a little local difficulty. A dispute has arisen over the decision by the Decimal Currency Board to use the full stop or point as a decimal marker, instead of the comma which is common in metric countries. The British Standards Institution, which is responsible for organizing the change to the decimal system in British industry, favours the comma, combined with a space to indicate thousands. The construction industry, the first to embrace metric units, has already begun to issue reports in this form. If the Decimal Currency Board is to have its way, both the BSI and the construction industry will have to think again.

The traditional system uses a full point for the decimal sign and a comma for indicating thousands; the new system supported by the BSI would use the comma for the decimal sign, and each group of three figures would be separated by a space. Thus the Decimal Currency Board would write 5,650.3286 and the BSI would prefer the form 5650,3286 . It is no secret that the joint metrication committee of the Ministry of Technology, an advisory body under the chairmanship of Mr A. H. A. Wynne, favours the system adopted by the Decimal Currency Board. Unlike most aspects of the metric system, there has so far been no international decision over which system to adopt, and this has made the committee's decision a difficult one. In reaching it, it took into account a number of factors.

First, there was the evidence provided by two questionnaires sent out by the BSI. The first, to the general engineering industry, produced inconclusive results. The second, which included financiers and merchant bankers, produced, predictably enough, a result in favour of traditional practices. The bankers felt that a system using empty spaces was an open temptation to fraud. The Decimal Currency Boarda notably conservative body-was swayed by much the same argument in favour of the traditional system. The Confederation of British Industry is also said to prefer the traditional system. In spite of this, the BSI continues to favour the space/comma system, and has written to the Decimal Currency Board to say so. The Ministry of Technology's answer to this is to say that, as long as there is no international system, it 